\title{
A PRODUÇÃO DE CONHECIMENTO SOBRE A BNCC COMO POLÍTICA CURRICULAR: CARACTERIZAÇÃO DAS PUBLICAÇÕES EM ARTIGOS, TESES E DISSERTAÇÕES
}

\section{THE PRODUCTION OF KNOWLEDGE ABOUT BNCC AS A CURRICULUM POLICY: CHARACTERIZATION OF PUBLICATIONS IN ARTICLES, THESES AND DISSERTATIONS}

\section{LA PRODUCCIÓN DE CONOCIMIENTO SOBRE BNCC COMO POLÍTICA CURRICULAR: CARACTERIZACIÓN DE LAS PUBLICACIONES EN ARTÍCULOS, TESIS Y DISERTACIONES}

\author{
Paulo Fioravante Giareta ${ }^{1}$ \\ Felipe de Lima Silva²
}

Fabiola Xavier Vieira Garcia ${ }^{3}$

\begin{abstract}
RESUMO: Este artigo tem por objetivo indicar as principais características das publicações sobre a Base Nacional Comum Curricular (BNCC) no Brasil classificadas como política curricular. As publicações classificadas como política curricular decorrem de um amplo levantamento sobre as publicações em artigos, teses e dissertações sobre a BNCC publicadas em Língua Portuguesa (Brasil) entre os anos de 2014 e 2020. O levantamento, por sua vez, está vinculado a um exercício ampliado de pesquisa que busca elucidar as características teórico-epistemológicas da produção de conhecimento sobre a BNCC a partir do aporte da metapesquisa, com o Enfoque das Epistemologias da Política Educacional. O texto mostra que as publicações sobre a BNCC, vinculadas à categoria política curricular, caracterizam-se pelo diálogo com outras políticas como as de gestão, avaliação e de formação de professores, bem como, com as diferentes etapas da educação básica brasileira.
\end{abstract}

Palavras-chave: Política Educacional. Política Curricular. Base Nacional Comum Curricular.

ABSTRACT: This article aims to indicate the main characteristics of publications on the Common National Curriculum Base (BNCC) in Brazil classified as curriculum policy. The publications classified as curricular policy result from a broad survey of publications in articles, theses and dissertations on the BNCC published in Portuguese (Brazil), between 2014 and 2020. The survey, in turn, is linked to an expanded research exercise that seeks to elucidate the theoretical and epistemological characteristics of the production of knowledge about BNCC, based on the contribution of meta-research, with the Focus on Epistemologies of Educational Policy. The text shows that publications on the BNCC, linked to the curriculum policy category, are characterized by dialogue with other policies such as management, evaluation and teacher formation, as well as with the different stages of Brazilian basic education.

Keywords: Educational Politics. Curriculum Policy. Common National Curriculum Base.

\footnotetext{
1 Universidade Federal de Mato Grosso do Sul, Brasil. E-mail: pfgiareta27@yahoo.com.br

(1D) https://orcid.org/0000-0002-0649-4756

2 Universidade Federal de Mato Grosso do Sul, Brasil. E-mail: felipelima_silva@outlook.com

(i) https://orcid.org/0000-0002-8671-747X

3 Universidade Federal de Mato Grosso do Sul, Brasil. E-mail: fabiolaxvg@adv.oabsp.org.br

(1) https://orcid.org/0000-0002-2030-7283
}

- Informações completas da obra no final do artigo 
Resumen: Este artículo tiene como objetivo señalar las principales características de las publicaciones en una Base Curricular Nacional Común (BNCC) en Brasil clasificada como política curricular. Las publicaciones clasificadas como política curricular proceden de un amplio estudio de publicaciones en artículos, tesis y conferencias sobre BNCC publicadas en portugués (Brasil), entre 2014 y 2020. La encuesta, a su vez, se vincula a un ejercicio de investigación ampliado que busca dilucidar las características teóricas y epistemológicas de la producción de conocimiento sobre la BNCC a partir del aporte de la meta-investigación, como Enfoque Epistemológico de la Política Educativa. El texto muestra que las publicaciones sobre la BNCC, vinculadas a la categoría política curricular, caracterizan el diálogo con otras políticas, como la gestión, la evaluación y la formación docente, así como las diferentes etapas de la educación básica brasileña.

Palabra clave: Política educativa. Política curricular. Base Curricular Común Nacional.

\section{Introdução}

A homologação do Plano Nacional de Educação (PNE, 2014 - 2024), Lei n. 13.005, de 25 de julho de 2014, no âmbito do sistema educacional brasileiro, formalizou o compromisso com a regularização da oferta da Educação Básica no Brasil a partir de uma base curricular comum.

A formalização deste ordenamento legal recebe contornos oficiais na aprovação pelo Conselho Nacional de Educação (CNE) da Resolução CNE_CP n. 2 de 22 de dezembro de 2017, que institui e orienta a implantação da Base Nacional Comum Curricular (BNCC) na educação básica brasileira. Esforço legal que será complementado, pelo próprio Conselho Nacional de Educação, com a aprovação da Resolução CNE_CP n. 4 de 17 de dezembro de 2018, esta, por sua vez, instituindo a Base Nacional Comum Curricular para o Ensino Médio.

As referidas resoluções expressam o resultado de profundas disputas políticopedagógicas que remontam os movimentos pela redemocratização brasileira na década de 1980 enquanto ampliação das relações institucionais e atendimento às demandas das relações produtivas, conferindo centralidade no contexto das políticas educacionais às políticas curriculares. Portanto, figuram como proposta de reforma educacional justificada pela Constituição Federal Brasileira de 1988 e pela Lei de Diretrizes e Bases da Educação Nacional (LDB) de 1996.

A Base Nacional Comum Curricular se apresenta, portanto, como reforma curricular, integrada à política nacional de educação básica, anunciada como capaz de promover profunda transformação na educação brasileira. Seu potencial de transformação é validado pela própria Resolução CNE/CP o 02 de 2017, ao prever, nas disposições finais e transitórias, que a BNCC terá incidência direta sobre os currículos das instituições e redes de ensino (Art. 15); sobre as matrizes de referência das avaliações e dos exames (Art. 16); 


\section{ENSIN@UFMS 2021}

ISSN 2525-7056

sobre a política de formação de professores (Art. 17); e sobre o Programa Nacional do Livro Didático (Art. 20).

Esta caracterização legal, normativa e político-pedagógica figura provocativa às pesquisas e à produção de conhecimento dos campos e agentes acadêmicos e científicos vinculados às políticas educacionais, que tem, neste texto, uma proposta de caracterização das publicações sobre a BNCC no Brasil, classificadas como política curricular. Ou seja, de um amplo levantamento em artigos científicos, teses e dissertações publicados no Brasil entre os anos de 2014-2020, num total de 602 publicações, 231 foram classificadas na categoria Política Curricular, enquanto publicações que abordam a BNCC no âmbito da política educacional brasileira como política de currículo.

Assim, o trabalho responde pelo objetivo de indicar possíveis características das publicações sobre a Base Nacional Comum Curricular (BNCC), classificadas como Política Curricular e sua consequente relação com o propagado ideário de transformação da educação brasileira.

O artigo se estrutura como um texto mais informativo do que crítico-analítico, propondo uma organização indicativa de possíveis características que emergem das publicações catalogadas e que indicam por um diálogo da BNCC como política curricular no âmbito do sistema educacional brasileiro. Este caráter informativo do texto serve, também, para o próprio referencial teórico-metodológico que orientou todo o processo de levantamento das publicações.

O trabalho se estrutura a partir de dois movimentos teóricos principais: primeiro, busca indicar uma aproximação rápida e informativa dos pressupostos teóricometodológicos que orientaram a pesquisa no seu conjunto; segundo, apresenta as características que emergem entre o conjunto de publicações vinculadas à categoria Política Curricular.

\section{Pressupostos Teórico-Metodológicos da Pesquisa}

O artigo, embora responda por um caráter mais informacional do que crítico-analítico, conforme já informado, posiciona-se a partir de um exercício ampliado de pesquisa que, por sua vez, responde pelo objetivo de identificar e analisar o conjunto de pesquisas teóricoempíricas decorrentes da elaboração e implantação da BNCC no sistema educacional 
brasileiro, bem como, elucidar sua caracterização teórico-epistemológica com aporte na proposta da metapesquisa, com Enfoque das Epistemologias da Política Educacional.

A metapesquisa é assumida, conforme define Mainardes (2021), como pesquisa sobre pesquisas, ou pesquisa sobre os processos de pesquisa desenvolvidos a partir de uma temática ou campo, respondendo como organização de estratégias para a análise do objeto de pesquisa. Portanto, enquanto pesquisa criteriosa e sistemática sobre as pesquisas, busca-se os fundamentos teóricos e os significados das pesquisas desenvolvidas sobre a BNCC.

O Enfoque das Epistemologias da Política Educacional, por sua vez, responde como enfoque/esquema de análise dos modos e processos de produção do conhecimento (TELLO, 2012; TELLO; MAINARDES, 2015). Esta abordagem se estruturada a partir dos componentes analíticos da perspectiva epistemológica, cosmovisão assumida pelo pesquisador no desenvolvimento da pesquisa; do posicionamento epistemológico, enquanto correntes teóricas do campo de estudo e posicionamento do pesquisador face ao objeto de investigação; e do enfoque epistemológico, como modo de construção metodológica da pesquisa (TELLO, 2012; TELLO; MAINARDES, 2015; MAINARDES, 2021).

Este aporte teórico, portanto, possibilita assumir a política educacional do currículo de forma integrada à política nacional de educação, espelhando como preocupação central a produção de conhecimento sobre as políticas educacionais.

O levantamento geral das publicações sobre a BNCC, que viabiliza o recorte categorial denominado de Política Curricular, foi realizado e organizado entre os meses de novembro de 2020 e fevereiro de 2021, considerando duas estratégias principais: I) levantamento das publicações em artigos científicos; II) e levantamento das publicações decorrente de pesquisas em Programas de Pós-Graduação no Brasil - teses e dissertações. Nos dois casos a busca se deu a partir de dois descritores: I) Base Nacional Comum Curricular; II) e BNCC.

O levantamento das publicações em artigos científicos foi realizado a partir da pesquisa em diversos sites de busca e repositórios:
a) Portal de Períodicos CAPES
b) Directory of Open Access Journals - Doaj
c) Sistemade Información Científica - Redalyc 
d) Scholar.google

e) Scielo Brasil

f) Crossref

O levantamento das publicações decorrente das pesquisas dos Programas de PósGraduação (teses e dissertações), por sua vez, se estruturou a partir de duas plataformas: Catálogo de Teses de Dissertações Capes; Biblioteca Digital Brasileira de Teses e Dissertações.

O levantamento completo resultou na identificação de 501 publicações em artigos científicos e 101 teses e dissertações, indicando um total de 602 publicações. O levantamento completo das publicações e sua organização a partir de categorias, já publicado por Giareta (2021), está, aqui, apresentado nos quadros 1 e 2:

Quadro 1: Categorização dos artigos sobre BNCC incluídos no levantamento (2014 - 2020)

\begin{tabular}{|l|c|}
\hline \multicolumn{2}{|c|}{ Artigos Científicos } \\
\hline Política Curricular & Quantidade \\
\hline Português e Literatura & 200 \\
\hline Matemática & 34 \\
\hline Fundamentos & 34 \\
\hline Ciências & 29 \\
\hline Educação Física & 27 \\
\hline Educação Infantil & 27 \\
\hline História & 27 \\
\hline Geografia & 22 \\
\hline Arte & 18 \\
\hline Ensino Religioso & 13 \\
\hline Educação Ambiental & 12 \\
\hline Alfabetização-Letramento & 12 \\
\hline Gênero e Sexualidade & 11 \\
\hline Língua Inglesa & 11 \\
\hline Sociologia & 11 \\
\hline Química & 04 \\
\hline Filosofia & 03 \\
\hline Física & 03 \\
\hline Estágio & 02 \\
\hline Total & 01 \\
\hline Fonte: Dados da pesqusa ongan & $\mathbf{5 0 1}$ \\
\hline
\end{tabular}

Fonte: Dados da pesquisa organizados pelos autores. 
Quadro 2: Categorização das teses e dissertações sobre BNCC incluídos no levantamento (2016 - 2020)

\begin{tabular}{|l|c|}
\hline \multicolumn{2}{|c|}{ Artigos Científicos } \\
\hline Descrição da Categoria & Quantidade \\
\hline Política Curricular & 31 \\
\hline Fundamentos & 15 \\
\hline Português e Literatura & 14 \\
\hline Educação Física & 09 \\
\hline Matemática & 08 \\
\hline História & 05 \\
\hline Alfabetização-Letramento & 02 \\
\hline Geografia & 03 \\
\hline Educação Infantil & 03 \\
\hline Ciências & 02 \\
\hline Ensino Religioso & 02 \\
\hline Língua Inglesa & 02 \\
\hline Gênero e Sexualidade & 02 \\
\hline Arte & 01 \\
\hline Educação Ambiental & 01 \\
\hline Química & 01 \\
\hline Total & $\mathbf{1 0 1}$ \\
\hline
\end{tabular}

Fonte: Dados da pesquisa organizados pelos autores.

\section{Caracterização das Publicações sobre a BNCC no Brasil Vinculadas à Categoria Política Curricular}

A preocupação com a política educacional do currículo, no âmbito da política educacional brasileira, ganha consistência a partir do contexto da redemocratização, com especial incidência sobre a Constituição de 1988 e a Lei de Diretrizes e Bases da Educação Nacional - LDB de 1996 -, que incorporam ao texto legal a necessidade de uma base comum nacional. Os primeiros esforços pela organização e implementação centralizada de uma política curricular com alcance nacional recebe materialidade oficial já na década de 1990, resultando na política dos Parâmetros Curriculares Nacionais - PCN -, que receberá contribuições das chamadas políticas de Diretrizes Curriculares Nacionais - DCN (MACEDO, 2014).

Os Parâmetros Curriculares Nacionais, documento com alto nível de detalhamento e objeto da crítica de pesquisadores da área das políticas educacionais, desde sua apresentação inicial, indica uma caracterização mais de política de controle do que de promoção curricular, resultando na sua definição como alternativa curricular não obrigatória e abrindo espaço para a elaboração de diretrizes curriculares mais gerais. A política das diretrizes, por sua vez, adentra a década de 2000 e demarca profundamente a política 
educacional brasileira, ao ponto de autores como Ciavatta e Ramos (2012) denominar todo o período pós décadas de 1990 como a era das diretrizes.

A adoção progressiva pelo sistema educacional brasileiro de indicadores de qualidade, alinhados aos modelos centralizados e externos de avaliação, as chamadas avaliações de larga escala e as políticas comparativas aos sistemas internacionais de avaliação, agenciados por organizações internacionais, comumente assentadas sobre matrizes avaliativas por competências e habilidades, tem acentuado o desconforto quanto aos resultados da educação nacional.

A referida preocupação com a qualidade educacional, a partir de indicadores padronizados por avaliações externas, tem justificado a retomada do debate por reformas na política curricular demandando, tanto revisitar o ideário de homogeneização de uma base curricular nacional, quanto a definição de uma matriz curricular alinhada à matriz avaliativa. A valorização deste ideário acaba por incidir sobre o próprio texto do Plano Nacional de Educação de 2014 - PNE 2014 -2024, formalizado na Lei 13.005 de 2014, que retoma a necessidade de uma base nacional comum.

Ainda, em 17 de julho de 2015, o Ministério da Educação publicou no Diário Oficial a Portaria n. 592, que instituiu a comissão de especialistas para a elaboração de proposta da Base Nacional Comum Curricular, apresentando a primeira versão em setembro do mesmo ano e a segunda versão em maio de 2016. A aprovação oficial se deu na terceira e quarta versão, respectivamente, pela Resolução CNE/CP nº 02, de 22 de dezembro de 2017 e pela Resolução CNE/CP nº 04, de 17 de dezembro de 2018, conforme já indicado no texto.

Assim, convém indicar de imediato que a BNCC se apresenta ao campo das políticas educacionais sob a marca do debate e das disputas político-pedagógicas em curso desde a década de 1990, razão pela qual não é estranho identificar que as publicações sobre a BNCC, indicadas no levantamento, espelham uma tendência à regularidade com poucas variações, ou seja, centradas majoritariamente na abordagem da BNCC como Política Curricular, seguida das produções sobre português, matemática e fundamentos, para na sequência abordar componentes curriculares como ciências, educação física, história e geografia, avançando para temáticas como ensino religioso, educação ambiental, gênero e sexualidade e, por fim, com menor demanda de publicações, os componentes como sociologia, química, filosofia e física, conforme demonstrado nos quadros 1 e 2. 
A maior centralidade conferida às publicações sobre a Base Nacional Comum Curricular como Política Curricular, objeto central deste texto, parece seguir a intencionalidade expressa na própria Resolução CNE/CP nํ 02 de 2017, ao apresentar a BNCC como reforma curricular integrada à política nacional de educação básica com potencial de promover profunda transformação na educação brasileira, indicando sua incidência como política educacional de currículo capaz de indução direta sobre os currículos das instituições e redes de ensino; sobre as matrizes de referência das avaliações e dos exames; sobre a política de formação de professores; e sobre o Programa Nacional do Livro Didático.

Esta caracterização legal reflete sobre o próprio esforço de produção de conhecimento da BNCC como Política Curricular ao apresentar artigos científicos (200) e teses e dissertações (31) que, tanto a discute como política curricular em si, quanto a discute de forma espelhada às demais políticas educacionais.

O esforço de produção de conhecimento sobre a Base Nacional Comum Curricular que busca apresentá-la e/ou a compreender como política educacional de currículo se evidenciam tanto nas publicações em artigos, quanto em teses e dissertações, conforme é demonstrado no quadro 3.

Quadro 3: Lista amostral de publicações sobre a BNCC vinculados à categoria Política Curricular que discutem a BNCC como política educacional do currículo

\section{ARTIGOS}

AGUIAR, Márcia Angela da Silva. Política Educacional e a Base Nacional Comum Curricular: o processo de formulação em questão. Currículo sem Fronteiras, v. 18, n. 3, p. 722-738, set./dez. 2018

ALBINO, Ângela Cristina Alves; ARAÚJO, Rute Pereira Alves de. Ser ou não Ser um Currículo? Contestações em torno da definição (anti)democrática da Base Nacional Comum Curricular. Linguagens, Educação e Sociedade, Teresina, ano 24, n. 41, p. 243-272, jan./abr. 2019.

ALMEIDA, Maria de Lourdes Pinto de; JUNG, Hildegard Susana. Políticas Curriculares e a Bse Nacional Comum Curricular: emancipação ou regulação? Educação, Santa Maria, v. 00, n. 00, p. 1-14, 2018

\section{TESES E DISSERTAÇÕES}

AVILA, Jaqueline Boeno D. As Influências dos Agentes Públicos e Privados no Processo de Elaboração da Base Nacional Comum Curricular. 27/03/2018, 129 f. Mestrado em Educação. Instituição de Ensino: Universidade Estadual do Centro-Oeste, Guarapuava, Biblioteca Depositária: Universidade Estadual do Centro-Oeste.

BRANCO, Emerson Pereira. A Implantação da BNCC no Contexto das Políticas Neoliberais. 08/11/2017, 136 f. Mestrado em Formação Docente Interdisciplinar. Instituição de Ensino: Universidade Estadual do Paraná - Reitoria, Paranavaí, Biblioteca Depositária: Unespar Paranavaí

Fonte: Dados de pesquisa organizados pelos autores. 
Os esforços empreendidos pela educação brasileira para garantir amplos e contínuos processos de reforma na sua política curricular, desde a década de 1990, receberam a contribuição direta e complementar da política de avaliação, especialmente, pela implementação de ampla política externa e em larga escala de avaliação do sistema educacional.

As pesquisas de Freitas (2014, p. 1092) ajudam a compreender esta relação e incidência prescritiva das políticas de avaliação externa com as políticas curriculares, que na prática parece espelhar a própria luta pelo controle do processo pedagógico das escolas desde fora. A BNCC ao conferir aderência à esta relação entre política curricular e política avaliativa reafirma o interesse em "preservar e aumentar o controle sobre os objetivos, o conteúdo e até sobre os métodos da escola".

Assim, a BNCC, enquanto política curricular, sob a justificativa de uma intervenção qualificada e em nome da progressiva qualidade da educação brasileira, indica pelo aprofundamento do controle e padronização do trabalho pedagógico em sala de aula esvaziando a ação dos profissionais da educação sobre o processo pedagógico (FREITAS, 2014).

Este apego a indicadores de qualidade vinculados aos sistemas de avaliação de larga escala reflete no próprio levantamento sobre as publicações, uma vez que fica visível o esforço de se produzir, no Brasil, conhecimento sobre a relação direta entre a BNCC como política curricular e a política de avaliação, conforme indicado no quadro 4.

Quadro 4: Lista amostral de publicações sobre a BNCC vinculados à categoria Política Curricular que discute a relação da BNCC com a política de avaliação

\section{ARTIGOS}

GONÇALVES, Amanda Melchiotti; GUERRA, Dhyovana; DEITOS, Roberto Antonio. Avaliação em Larga Escala e a Base Nacional Comum Curricular (BNCC): dimensões da política de contenção e liberação no Brasil. RPGE- Revista online de Política e Gestão Educacional, Araraquara, v. 24, n. esp. 1, p. 891908, ago. 2020

BARRETO, Raquel Goulart. Entre a Base Nacional Comum Curricular e a Avaliação: a substituição tecnológica no ensino fundamental. Educação \& Sociedade, Campinas, v. 37, n. 136, p. 775-791, jul.-set. 2016

BRUNS, Juliana Pedroso; NUNES, Camila da Cunha. Implicações da Base Nacional Comum Curricular sobre a Avaliação no 1ํㅡㄹ Ano do Ensino Fundamental a partir da Visão dos Professores. EDUCA - Revista Multidisciplinar em Educação, Porto Velho, v. 6, n. 16, p. 210-229, out./dez., 2019

TESES E DISSERTAÇÕES 
MAIER, Thays Trindade. Avaliações em Larga Escala - Prova Brasil e Prova ANA: análise das relações com a BNCC 2014-2019. 2020, 140 f. Dissertação (Programa de Pós-Graduação em Educação) - Universidade Estadual do Oeste do Paraná, Cascavel - PR.

Fonte: Dados de pesquisa organizados pelos autores.

O alcance efetivo de qualquer reforma educacional, também da reforma curricular, num sistema educacional como o brasileiro, sempre figura dependente da capacidade de envolvimento e diálogo dos promotores da proposta com os sujeitos político-pedagógicos da escola, especialmente, os professores.

Figura pertinente indicar que concomitante à realização desta pesquisa, o Conselho Nacional de Educação garantiu a aprovação da Resolução CNE/CP № 2, de 20 de dezembro de 2019, que define as Diretrizes Curriculares Nacionais para a Formação Inicial de Professores para a Educação Básica e institui a Base Nacional Comum para a Formação Inicial de Professores da Educação Básica, propondo uma aproximação obediente dos projetos de formação de professores à lógica da Base Nacional Comum Curricular.

Assim, soma-se ao ideário de política curricular prescritiva, alinhada às regulações promovida pelas políticas de avaliação externa, uma adequação regulada da própria política de formação dos professores face a política da BNCC, guardando sintonia e indicando o aprofundamento da já indicada lógica homogeneizante e de controle (FARIAS, 2019).

Esta orientação reflete nas publicações, figurando como uma das marcantes características da produção de conhecimento sobre a BNCC, conforme é demonstrado no quadro 5.

Quadro 5: Lista amostral de publicações sobre a BNCC vinculados à categoria Política Curricular que discutem a relação da BNCC com a política de formação de professores

\section{ARTIGOS}

AGUIAR, Márcia Angela da Silva; DOURADO, Luiz Fernandes. BNCC e Formação de Professores: concepções, tensões, atores e estratégias. Revista Retratos da Escola, Brasília, v. 13, n. 25, p. 33-37, jan./mai. 2019.

CERICATO, Itale; CERICATO, Lauri. A Formação de Professores e as novas Competências Gerais Propostas pela BNCC. Revista Veras, São Paulo, v. 8, n. 2, p. 137-149, julho/dezembro, 2018

COSTA, Cristiana Marinho da. Diálogo Acerca das Competências Socioemocionais e suas Interfaces com a BNCC e a Formação Docente. Revista Internacional Educon, v. I, n.1, p. 1-13, set./dez. 2020

\section{TESES E DISSERTAÇÕES}

PEREIRA, Karla Cristina Prudente. A BNCC do Ensino Médio e suas Implicações para Formação e Trabalho dos Professores. 18/12/2019, 79 f. Mestrado em Formação Docente Interdisciplinar. Instituição de Ensino: Universidade Estadual do Paraná - REITORIA, Paranavaí, Biblioteca Depositária: Unespar

Fonte: Dados de pesquisa organizados pelos autores 
A orientação curricular de política avaliativa e formação de professores, assumida pela BNCC como política curricular, necessariamente, precisa impactar, também, a política de gestão da escola, com especial aceno para a gestão pedagógica da escola enquanto condição para sua implementação.

Os já indicados esforços de reforma educacional movimentados pelo Estado brasileiro, desde a década de 1990, com centralidade para as reformas curriculares, alinhadas a um conjunto de políticas construídas desde fora da escola, precisa se expressar como movimento capaz de reformar a própria cultura escolar, portanto, de seus rituais e práticas de gestão político-pedagógica.

Este ordenamento vem ganhando contorno no que pesquisadores, como Oliveira (2019), denominam de nova gestão pública, enquanto esforço da agenda neoliberal em conferir centralidade às estratégias de controle, eficácia e eficiência do Estado, que no âmbito da educação responde pela nova gestão escolar, espelhando o mesmo ideário.

As publicações sobre a BNCC classificadas na categoria Política Curricular respondem a este disciplinamento indicando ser a política de gestão uma das características que emerge do esforço de produção de conhecimento sobre a BNCC, conforme é demonstrado no quadro 6.

Quadro 6: Lista amostral de publicações sobre a BNCC vinculados à categoria Política Curricular que discutem a relação da BNCC com a política de gestão escolar

\section{ARTIGOS}

ANTUNES, Marina Ferreira de Souza. O Currículo como Materialização do Estado Gerencial: a BNCC em questão. Movimento-Revista de Educação, Niterói, ano 6, n.10, p. 43-64, jan./jun. 2019

AUGUSTINI, Rudinei Barichello. A Base Nacional Comum Curricular e a Superação de Conflitos em um Projeto Educativo. Momento: Diálogos em Educação, v. 28, n. 3, p. 366-389, set./dez, 2018

CARVALHÉDO, Josania Lima Portela. Gestão da Escola Básica Pública e BNCC: quais as implicações?

Revista Exitus, Santarém/PA, v. 10, p. 01-12, 2020

\section{TESES E DISSERTAÇÕES}

PIRES, Mônica Dias Medeiros. A Influência Empresarial na Política Curricular Brasileira: um estudo sobre o Movimento pela Base Nacional Comum. 2020, 360f. Dissertação - Faculdade de Educação, Universidade Federal de Juiz de Fora, Juiz de Fora, 2020

Fonte: Dados de pesquisa organizados pelos autores.

Ainda, convém destacar a produção de conhecimento sobre a BNCC e sua relação como política educacional de currículo, com as etapas - Educação Infantil, Ensino 
Fundamental e Ensino Médio - da educação básica brasileira como uma de suas características.

Conforme já indicado no texto, a homologação da Base Nacional Comum Curricular, pelo Conselho Nacional de Educação, dá-se em dois momentos distintos. A Resolução CNE_CP n. 2 de 22 de dezembro de 2017 responde pela instituição da BNCC para a Educação Infantil e Ensino Fundamental, restando à Resolução CNE_CP n. 4 de 17 de dezembro de 2018 a instituição da BNCC para a etapa do Ensino Médio.

Este hiato temporal na aprovação das propostas não inibe a necessidade legal de implementação da BNCC, inicialmente prevista para o início do ano letivo de 2020, o que resulta em forte movimento de produção intelectual entre os pesquisadores do campo da educação, buscado compreender seus impactos para as respectivas etapas da educação básica.

O que possibilita afirmar que estes esforços de produção de conhecimento sobre 0 impacto da BNCC nas respectivas etapas da educação básica resultam em uma de suas características, conforme é demonstrado no quadro 7.

Quadro 7: Lista amostral de publicações sobre a BNCC vinculados à categoria Política Curricular que discutem a relação da BNCC com as etapas da educação básica

\section{ARTIGOS}

ARAÚJO, Edimilson Pereira de. Currículo de Educação Infantil: perspectivas a partir da Base Nacional Comum Curricular. Revista Educere Et Educare, vol. 15, n. 36, Especial Educere, p. 1-16, Out. 2020.

ORNELLAS, Janaína Farias de; SILVA, Luana Cristeinsen. O Ensino Fundamental da BNCC: proposta de um currículo na contramão do conhecimento. Revista Espaço do Currículo (online), João Pessoa, v. 12, n. 2, p. 309-325, maio/ago. 2019

BRANCO, Alessandra Batista de Godoi; BRANCO, Emerson Pereira; IWASSE, Lilian Fávaro Algrâncio; NAGASHIMA, Lucila Akiko. Urgência da Reforma do Ensino Médio e Emergência da BNCC. Revista Contemporânea de Educação, v. 14, n. 29, p. 345-363, jan/abr. 2019

\section{TESES E DISSERTAÇÕES}

COELHO, Eliane Siqueira costa. A BNCC e o Processo de Ensino e de Aprendizagem nos anos Iniciais do Ensino Fundamental: uma proposta definida por ações. 24/09/2019, $132 \mathrm{f}$. Mestrado em LETRAS E LINGUÍSTICA. Instituição de Ensino: Universidade do Estado do Rio de Janeiro, São Gonçalo, Biblioteca Depositária: UERJ CEHD REDE SIRIUS

LIMA, Maria Daniele Coelho. Os Impactos da Proposta da Base Nacional Comum Curricular para o Ensino Médio. 28/06/2019, 94 f. Mestrado em EDUCAÇÃO. Instituição de Ensino: Centro Universitária Moura Lacerda, Ribeirão Preto, Biblioteca Depositária: JOSEFINA DE SOUZA LACERDA

Fonte: Dados de pesquisa organizados pelos autores. 


\section{ENSIN@UFMS 2021}

ISSN 2525-7056

\section{Considerações Finais}

O olhar para a produção de conhecimento sobre a Base Nacional Comum Curricular, de imediato, explicita o seu caráter de política em disputa no atual contexto da política educacional brasileira. Esta disputa fica explícita, tanto pelo volume de produção sobre a BNCC: 501 publicações em artigos e 101 teses e dissertações, quanto pela centralidade das publicações que discutem a BNCC como política curricular: 200 publicações em artigos e 31 em teses e dissertações.

Considerando especificamente as publicações vinculadas à categoria Politica Curricular, figura pertinente reconhecer uma amplitude de abordagens que indicam o alcance da BNCC no âmbito da política educacional em dialogar com áreas como política de formação de professores, política de avaliação e política de gestão da educação, que em última análise, indicam pela intensificação dos processos de disputa na educação brasileira.

Esta disputa se manifesta, também, no movimento de percepção do alcance e impacto da proposta da política curricular da BNCC nas etapas da educação básica Educação Infantil, Ensino Fundamental e Ensino Médio - concentrando o esforço de teóricos e pesquisadores da área.

A percepção das referidas características, no entanto, demanda um olhar aprofundado, capaz de possibilitar a leitura dos fundamentos teórico-metodológicos que orientam este conjunto de produções, consequentemente, a capacidade da BNCC em intervir de forma qualificada na educação brasileira. Pelo que resta indicado a continuidade das pesquisas buscando os fundamentos epistemológicos destas produções.

\section{Referências}

BRASIL. Constituição de (1988). Constituição da República Federativa do Brasil. Brasília. Senado Federal, 1998.

BRASIL. Ministério da Educação. Lei no 9.394/1996. Diretrizes e Bases da Educação Nacional. Brasília, 1996.

BRASIL. Lei 13.005 de junho de 2014. Plano Nacional de Educação - PNE 2014-2024. Disponível em: http://www.planalto.gov.br/ccivil_03/_ato2011-2014/2014/lei//13005.htm Acesso em 10 abr. 2021.

BRASIL. Conselho Nacional de Educação. Resolução no 02 de 22 de dezembro de 2017. Base Nacional Comum Curricular. Brasília. 2017. Disponível em: 
http://basenacionalcomum.mec.gov.br/images/historico/RESOLUCAOCNE_CP222DEDEZ EMBRODE2017.pdf Acesso em 10 abr. de 2021.

BRASIL. Conselho Nacional de Educação. Resolução no 04 de 17 de dezembro de 2018. Disponível em:

https://www.in.gov.br/materia//asset_publisher/Kujrw0TZC2Mb/content/id/55640296 Acesso em 10 abr. 2021.

CIAVATTA, M; RAMOS, M. A "era das diretrizes": a disputa pelo projeto de educação dos mais pobres. Revista Brasileira de Educação. v. 17. no 49, jan/abr. 2012.

FARIAS, I. M. S. O discurso curricular da proposta para BNC da formação de professores da educação básica. Revista Retratos da Escola, Brasília, v. 13, n. 25, p. 155-168, jan./maio 2019. DOI: https://doi.org/10.22420/rde.v13i25.961

FREITAS, L. C. de. Os reformadores empresariais da educação e a disputa pelo controle do processo pedagógico na escola. Educação \& Sociedade, Campinas, v. 35, n. 129, p. 1085-1114, out./dez. 2014

GIARETA, P. F. A produção de conhecimento sobre a Base Nacional Comum Curricular no Brasil: levantamento de teses, dissertações e artigos. Revista de Estudios Teóricos y Epistemológicos en Política Educativa. v.6, p. 1-38, 2021.

MACEDO, E. Base Nacional Comum Curricular: novas formas de sociabilidade produzindo sentidos para a educação. Revista e-Curriculum. São Paulo. V. 12, no 03, p. 1530 - 1555, out/dez. de 2014.

MAINARDES, J. A metapesquisa no campo da Política Educacional: aspectos teóricos, conceituais e metodológicos. In: MAINARDES, J. Metapesquisa no campo Política Educacional. Curitiba: CRV, 2021. p. 19-43.

OLIVEIRA, R.T.C. de. As mudanças nas formas de gestão escolar no contexto da nova gestão pública no Brasil e em Portugal. Educar em Revista. Curitiba, Brasil, v. 35, n.74, p. 213-232, mar.-abr. 2019

TELLO, C; MAINARDES, J. Revisitando o enfoque das epistemologias da política educacional. Práxis Educativa, Ponta Grossa, v. 10, n. 1, p. 153 -178, 2015.

TELLO, C. Las epistemologias de la política educativa: vigilância y posicionamento epistemológico del investigador em política educativa. Práxis Educativa, Ponta Grossa, v. 7, n. 1, p. $53-68,2012$.

\section{NOTAS}

\section{IDENTIFICAÇÃO DE AUTORIA}

Paulo Fioravante Giareta. Pós-Doutorando no Programa de Pós-Graduação em Educação da Universidade Estadual de Ponta Grossa (UEPG). Professor do Programa de Pós-Graduação em Educação 
(PPGEdu_CPTL) da Universidade Federal de Mato Grosso do Sul (UFMS), Campus de Três Lagoas (CPTL). Líder do Grupo de Estudo e Pesquisa em Formação de Professores (GForP) da UFMS/CPTL. Três Lagoas, MS, Brasil.

E-mail: pfgiareta27@yahoo.com.br

(i) https://orcid.org/0000-0002-0649-4756

Felipe de Lima Silva. Bolsista da Fundação de Apoio ao Desenvolvimento do Ensino, Ciência e Tecnologia do estado de Mato Grosso do Sul (FUNDECT). Mestrando no Programa de Pós-Graduação em Educação (PPGEdu_CPTL) da Universidade Federal de Mato Grosso do Sul (UFMS), Campus de Três Lagoas (CPTL), Três Lagoas, MS, Brasil.

E-mail: felipelima_silva@outlook.com

(iD https://orcid.org/0000-0002-8671-747X

Fabiola Xavier Vieira Garcia. Graduada em Direito (Universidade de Marília). Pós graduada "Lato Sensu" em Direito do Trabalho (Univel). Mestranda no Programa de Pós-Graduação em Educação (PPGEdu_CPTL) da Universidade Federal de Mato Grosso do Sul (UFMS), Campus de Três Lagoas (CPTL), Três Lagoas, MS, Brasil.

E-mail: fabiolaxvg@adv.oabsp.org.br

(i) https://orcid.org/0000-0002-2030-7283

\section{AGRADECIMENTOS}

Não se aplica.

\section{FINANCIAMENTO}

Não se aplica.

CONSENTIMENTO DE USO DE IMAGEM

Não se aplica.

\section{APROVAÇÃO DE COMITÊ DE ÉTICA EM PESQUISA}

Não se aplica.

\section{LICENÇA DE USO}

Autores mantêm os direitos autorais e concedem à revista ENSIN@ UFMS - ISSN 2525-7056 o direito de primeira publicação, com o trabalho simultaneamente licenciado sob a Licença Creative Commons Attribution (CC BY-NC-SA 4.0), que permite compartilhar e adaptar o trabalho, para fins não comerciais, reconhecendo a autoria do texto e publicação inicial neste periódico, desde que adotem a mesma licença, compartilhar igual.

\section{EDITORES}

Patricia Helena Mirandola Garcia, Eugenia Brunilda Opazo Uribe, Gerson dos Santos Farias.

\section{HISTÓRICO}

Recebido em: 02/11/2021 - Aprovado em: 20/11/2021 - Publicado em: 06/12/2021.

\section{COMO CITAR}

GIARETA, P. F; SILVA, F. L; GARCIA, F. X. V. A Produção de Conhecimento sobre a BNCC como Política Curricular: Caracterização das Publicações em Artigos, Teses e Dissertações. Revista ENSIN@ UFMS, Três Lagoas, v. 2, n. 6, p. 19-33. 2021. 